\title{
Perianal disease onset age is associated with distinct disease features and need for intestinal resection in perianal Crohn's disease: a ten-year hospital-based observational study in China
}

Haichao Wang ${ }^{1+}$, Yaling $\mathrm{Wu}^{1+}$, Chen Ye ${ }^{2}$, Zhanju Liu' ${ }^{1}$ and Xiaolei Wang ${ }^{1 *}$

\begin{abstract}
Background and aims: The significance of different ages of perianal disease (PD) onset in patients with perianal Crohn's disease (PCD) remains unknown. We aimed to investigate the impact of paediatric-onset PD (POP) and adultonset PD (AOP) on the Crohn's disease (CD) course in a Chinese cohort.

Methods: The medical records of diagnosed PCD patients from 2008 to 2018 were reviewed retrospectively. The cumulative incidence and predictors of intestinal resection were calculated using the Kaplan-Meier and logistic regression analysis.

Results: Complex perianal fistulas $(71.7 \%$ vs $50.0 \%, p=0.011)$ and infliximab (IFX) treatment (33.3\% vs 22.0\%, $p=0.044$ ) were more common among the POP patients (age $<18$ years old, $\mathrm{n}=84$ ). A younger PD onset age $(15.1 \pm 2.9$ vs $30.2 \pm 10.5$ years, $p<0.001)$ and shorter PCD diagnostic delay ( 12 vs 24 months, $p=0.033$ ) was found in the POP cohort. AOP patients (age $\geq 18$ years old, $n=209$ ) had a higher rate of current smoking $(12.9 \%$ vs $4.8 \%$, $p=0.040$ ), stricturing behaviour ( $42.1 \%$ vs $27.4 \%, p=0.024)$ and intestinal resection $(21.1 \%$ vs $4.8 \%, p=0.001)$. The cumulative probability of intestinal resection in AOP patients was higher than that in POP patients $(p=0.007)$. In multivariable analysis, AOP (OR: 4.939, 95\% Cl 1.538-15.855, $p=0.007$ ), stricturing behaviour (OR: $1.810,95 \% \mathrm{Cl}$ $1.008-3.251, p=0.047$ ) and rectal inflammation (OR: 3.166, 95\% Cl 1.119-8.959, $p=0.030$ ) were predictive factors for CD-related intestinal resection in all PCD patients. AOP patients with complex perianal fistula (OR: $2.257,95 \% \mathrm{Cl}$ $1.041-4.891, p=0.039$ ) and POP patients with rectal inflammation (OR: 3.166, 95\% Cl 1.119-8.959, $p=0.030$ ) were more likely to suffer intestinal resection. The IFX administration significantly decreased the rate of intestinal resection in AOP patients ( $r=-0.900, p=0.037$ ).

Conclusions: The AOP patients have more complicated luminal disease and higher rate of intestinal resection than COP patients. The perianal diseases onset-age can provide clinical treatment guidance for individual management of CD patients.
\end{abstract}

\footnotetext{
*Correspondence: wangxiaolei@tongji.edu.cn

${ }^{\dagger}$ Haichao Wang and Yaling Wu have contributed equally to this paper.

1 Department of Gastroenterology, Shanghai Tenth People's Hospital,

School of Medicine, Tongji University, Shanghai 200072, China

Full list of author information is available at the end of the article
}

(C) The Author(s) 2021. Open Access This article is licensed under a Creative Commons Attribution 4.0 International License, which permits use, sharing, adaptation, distribution and reproduction in any medium or format, as long as you give appropriate credit to the original author(s) and the source, provide a link to the Creative Commons licence, and indicate if changes were made. The images or other third party material in this article are included in the article's Creative Commons licence, unless indicated otherwise in a credit line to the material. If material is not included in the article's Creative Commons licence and your intended use is not permitted by statutory regulation or exceeds the permitted use, you will need to obtain permission directly from the copyright holder. To view a copy of this licence, visit http://creativecommons.org/licenses/by/4.0/. The Creative Commons Public Domain Dedication waiver (http://creativeco mmons.org/publicdomain/zero/1.0/) applies to the data made available in this article, unless otherwise stated in a credit line to the data. 
Keywords: Perianal disease, Crohn's disease, Paediatric onset, Adult-onset, Intestinal resection

\section{Introduction}

Crohn's disease (CD) is a multifactorial systemic inflammatory bowel disease (IBD) with a heterogeneous clinical course. Perianal disease (PD) is a common complication in CD patients and can lead to a low quality of life, a high rate of surgical interventions, and challenging therapeutic situations [1-3]. Patients with perianal Crohn's disease (PCD) undergo a number of perianal surgical interventions (PSIs), resulting in multiple disabilities. However, the successful development of various anti-tumour necrosis factor (TNF)- $\alpha$ agents (the first biological agents for $C D$ in the world) breaks this impasse. Due to their rapid efficacy in cases of complicated PD and luminal lesions, anti-TNF agents, including infliximab (IFX) and adalimumab, are recommended as the first-line treatment for $C D$ patients who have high-risk factors for poor outcomes, including PD, onset age $<40$ years, and extensive small bowel involvement [4-10]. In China, IFX was the only available anti-TNF agent for CD from 2008 to 2018 and showed a more favourable perianal and luminal outcomes than traditional treatment in both children and adult PCD patients $[11,12]$. There is some evidence that the prevalence of PCD was higher in Asian than Western countries, and the outcomes of Asian PCD patients may differ from those of Western patients [13-15]. However, Chinese studies evaluating the characteristics and outcomes of PCD patients are limited.

Patients with PCD usually have a higher risk of abdominal surgery. However, this increased risk only reached statistical significance in patients who developed PD during follow-up, but not in patients who presented with PD before or at luminal CD diagnosis [1]. This finding indicates that the PD onset time plays an important role in the $\mathrm{CD}$ natural history. Approximately $25 \%$ of CD patients are diagnosed in childhood or adolescence [16]. Interestingly, different features have been found between paediatric- and adult-onset $\mathrm{CD}$ patients. For example, paediatric CD patients had a three-times higher risk of progressing to complicated $\mathrm{CD}$ than adult-onset $\mathrm{CD}$ patients [17] and required more intensive pharmacological treatments [17-19]. However, Schoepfer, A., et al. reported that adult CD patients present more bowel surgery and longer diagnostic delay (the time interval between the first symptom and diagnosis of $\mathrm{CD}$ ) compared with paediatric $\mathrm{CD}$ patients. And a long diagnostic delay was found to be predictive for an increased incidence of CD-related surgery only in the adult but not in the paediatric CD patients [18]. The diagnosis of perianal fistulas after the luminal CD was reported to range from 5 to $21 \%$ in adult $C D$ patients and $8 \%$ to $27 \%$ in paediatric $C D$ patients [4-7]. These suggest that onset-age plays an important role in the $C D$ disease course. However, whether the onset-age of $\mathrm{PD}$ is associated with the incidence of CD-related intestinal resection is still unknown. Therefore, we aimed to evaluate the measurable differences in clinical outcomes between PCD patients with paediatric-onset PD (POP) and adultonset $\mathrm{PD}$ (AOP) and to identify clinical predictive factors of the development of intestinal resection in this ten-year follow-up study.

\section{Materials and methods Patients}

We retrospectively evaluated 747 consecutive CD patients in the Tenth People's Hospital affiliated with Tongji University (Shanghai, China) from January 2008 to December 2017. Eligible patients were confirmed $\mathrm{CD}$ patients having PD involvement during the disease course. Both the PD presented before and after diagnosis of CD were included in the study. The diagnosis of $\mathrm{CD}$ in paediatric patients was based on the Porto criteria [20], and the diagnosis of $C D$ in adult patients satisfied the criteria published by the European Crohn's and Colitis Organization [21]. PD was diagnosed according to presence of perianal symptoms, results of clinical examinations, perianal ultrasound and/or magnetic resonance imaging. Patients who were lost to follow-up or had incomplete clinical information were excluded. The follow-up period refers to the period from the first hospitalization to the last hospitalization within the end of data collection (December 31, 2018). Patients were followed up at each visit in hospital according to the medical records, and occasional telephone consultation. The patients with follow-up period less than 3 months were excluded. The study protocol was reviewed and approved by the Institutional Ethics Committee of the Tenth People's Hospital affiliated with Tongji University, Shanghai, China (SHSY- IEC- 4.0/19 -23/01), and got an exemption from informed consent because of the retrospective study design.

\section{Description of variables and outcomes}

The medical records were reviewed for sex, PD onset age, $\mathrm{PD}$ type, age at $\mathrm{CD}$ diagnosis, age at $\mathrm{PCD}$ diagnosis, PCD diagnostic delay, clinical manifestations, Montreal classification, smoking status, family history of 
IBD, CD-related medications and surgical interventions (perianal and abdominal interventions). CD-related medical treatment included antibiotics (imidazole and quinolones), immunosuppressants (azathioprine and methotrexate), corticosteroids and IFX. IFX was regularly administered intravenously at a dose of $5 \mathrm{mg} / \mathrm{kg}$ body weight at 0,2 , and 6 weeks and then every 8 weeks. The duration of IFX treatment was calculated from the first infusion to the last infusion within the follow-up period. The PSIs included perianal abscess incision and drainage, seton insertion, fistulectomy, de-functioning surgery, and proctectomy. CD-related abdominal surgery in this study mainly referred to $\mathrm{CD}$-related intestinal resection, including the partial ileal resection, partial colon resection, ileocolonic resection.

POP was defined as PD with an onset age of less than $18(<18)$ years, and AOP was defined as PD with an onset age of greater than or equal to $18(\geq 18)$ years [18]. The types of PD were classified according to a technical review by the American Gastroenterology Association at the time of PD diagnosis and included perianal skin lesions (anal skin tags and haemorrhoids), anal canal lesions (anal fissures, ulcers, and anorectal strictures), perianal abscesses, perianal fistulas, rectovaginal fistulas, and cancer [22]. Perianal fistulas were classified into simple and complex fistulas. Simple perianal fistulas are low in position (superficial, low intersphincteric or low transsphincteric origin of the fistula tract) and have only a single external opening without evidence to suggest perianal abscesses, anorectal strictures or rectovaginal fistulas. Complex perianal fistulas originate from a high position (intersphincteric, transsphincteric, extrasphincteric, or suprasphincteric region) and usually have multiple external openings combined with perianal abscesses, anorectal structures, or rectovaginal fistulas [22]. PCD diagnostic delay is defined as the time interval between the first diagnosis of PD and luminal CD. The first diagnosis of PD depends on the exact medical records of the electronic system in our hospital or the accurate data records in other hospitals provided by patients themselves. The diagnosis of luminal CD is defined by the findings of endoscopy in our hospital or endoscopic report in the other hospitals.

The clinical outcomes of PD were categorized as clinical remission, non-remission and recurrence. Clinical remission was defined as follows: (1) no perianal symptoms (e.g., local swelling and pain, haematochezia, faecal incontinence); (2) closure of the external opening of perianal fistulas; (3) no visible internal openings, perianal abscesses or anal ulcers; and (4) absence of drainage despite gentle finger compression. Non-remission referred failure to achieve clinical remission after a certain therapeutic strategy or maintain clinical remission for less than 3 months. Recurrence was defined as the presence of new PD after 3 months of clinical remission.

\section{Statistical analyses}

Categorical variables are described as counts with percentages and were assessed by the chi-square test or Fisher's exact test. Continuous variables are described as the mean \pm standard deviation (SD) or median plus interquartile range (IQR) and were analysed by the independent sample t-test or the Mann-Whitney test. The factors associated with CD-related surgery were analysed by univariate and multivariate analyses. Multivariate logistic regression analysis was performed for factors with a $p$ value $<0.2$ in the univariate analysis by the enter method (Wald test used for assessing $p$ values). Kaplan-Meier analysis was applied to calculate the cumulative probabilities of IFX treatment and CD-related intestinal resection during the 10-year follow-up period. A log-rank comparison was used to compare the cumulative probabilities between the two groups of patients with POP and AOP. Spearman correlation coefficients were calculated between the rates of $\mathrm{CD}$-related intestinal resection and the percentages of patients treated with IFX. Two-sided $p$ values $<0.05$ were considered statistically significant. SPSS 22.0 software (IBM, Sommers, NY, USA) was used for statistical analysis.

\section{Results}

\section{Characteristics of PCD patients with POP and AOP}

Among 747 well-characterized CD patients, 293 (39.2\%) patients with perianal involvement were enrolled. The median follow-up duration among the 293 PCD patients was 72 (IQR: 36-108) months. Two hundred and four (69.6\%) patients had the one type of perianal diseases, 68 (23.2\%) having two types of PD, and 17 (5.8\%) patients having three and over three types of PD during the disease course. Perianal fistula was the most common PCD $(163 / 293,55.6 \%)$, with complex phenotypes in $57.1 \%$ (93/163) of cases. One hundred forty-one (48.1\%) PCD patients had perianal abscesses, and 51 (17.4\%) had haemorrhoids. Anal ulcers, fissures and rectovaginal fistula and were seen in only $5.1 \%(15 / 293), 4.4 \%(13 / 293)$ and $3.4 \%(10 / 293)$ of PCD patients, respectively. No cases of cancer were identified during follow-up. The mean onset age of PD was $25.9 \pm 11.3$ years old. The AOP cohort comprised 209 (71.3\%) patients, and the POP cohort included 84 cases (28.7\%). There was a gradual increase in the diagnosis of POP in PCD patients from 2008.1 to 2017.12 but a reduction in the diagnosis of patients with AOP during the same period (Fig. 1).

The baseline characteristics of these two groups of patients were summarized in Table 1. Most POP (81.0\%) and AOP (73.7\%) patients were male. Among POP 
patients, the mean age at diagnosis of CD $(18.0 \pm 4.3 \mathrm{vs}$ $32.0 \pm 10.9$ years, $p<0.001)$ and at onset of PD $(15.1 \pm 2.9$ vs $30.2 \pm 10.5$ years, $p<0.001)$ was significantly younger than that among AOP patients (Table 1). The median duration of PCD diagnostic delay (12 [IQR: 2-48] vs 24 [IQR: $2.5-60]$ months, $p=0.033$ ) was shorter in the POP cohort. Compared to AOP patients, POP patients presented with a higher proportion of complex perianal fistulas $(71.7 \%$ vs $50.0 \%, p=0.011)$ and non-stricturing and non-penetrating (B1) behaviour (66.7\% vs $47.8 \%$, $p=0.005)$. Stricturing type (B2) behaviour $(42.1 \%$ vs $27.4 \%, p=0.024)$ and current smoking $(12.9 \%$ vs $4.8 \%$, $p=0.040)$ were more common among AOP patients than POP patients (Table 1 ).

A total of 253 patients received initial treatment for PD. Among them, PSIs combined with antibiotic treatment was performed on half of the PCD patients (153/293, 52.2\%), then followed by IFX treatment after PSIs (36/293, 12.3\%), IFX monotherapy (30/293, 10.2\%), antibiotic monotherapy $(26 / 293,8.9 \%)$ and IFX combined with immunosuppressants (8/293, 2.7\%). Two hundred forty-six PCD patients achieved clinical remission of PD after initial treatment, including 71 POP patients $(84.5 \%)$ and 175 AOP patients $(83.7 \%)$. Of the 246 patients who achieved clinical remission, 60 (24.4\%) patients experienced PD recurrence during the follow-up period, including $21(29.6 \%, 21 / 71)$ POP patients and 39 $(22.3 \%, 39 / 175)$ AOP patients. The types of PD experiencing recurrence included 11 (52.4\%) perianal abscess, 9 (42.9\%) perianal fistulas, one (4.8) anal fissure, but no rectovaginal fistula in 21 POP patients. These frequencies in 39 AOP patients were 19 (48.7\%), 19 (48.7\%), 0 $(0 \%)$ and $1(2.6 \%)$, respectively $(p=0.609)$. No significant

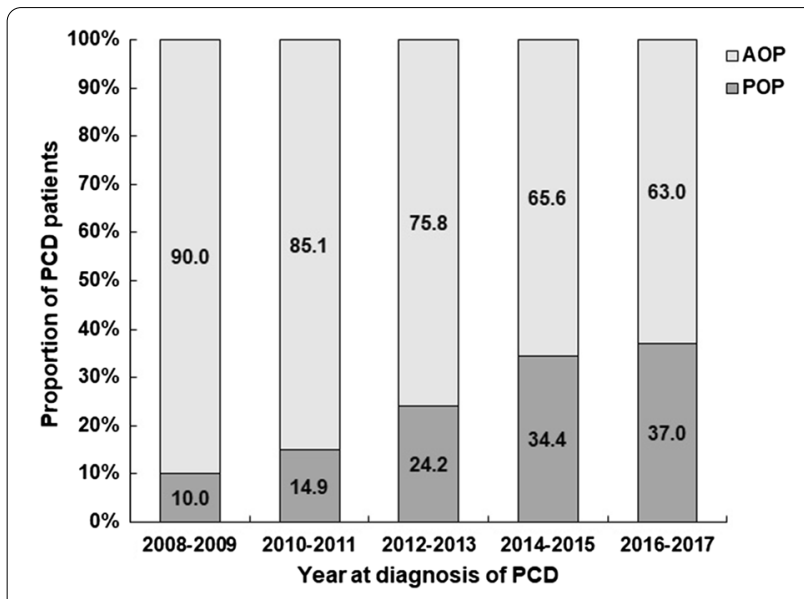

Fig. 1 Proportion of PCD patients with different perianal disease onset ages between 2008 and 2017. PCD perianal Crohn's disease, $P O P$ paediatric-onset perianal disease, $A O P$ adult-onset perianal disease difference in the disease location, PSI frequency, PSI type or family history of IBD was observed between the two groups of patients $(p>0.05$, Table 1$)$.

\section{IFX treatment}

Seventy-four patients $(25.5 \%, 74 / 293)$ receiving IFX treatment for active PD (perianal fistulas, perianal abscess and rectovaginal fistulas) after the first diagnosis of PCD. Those PCD patients requiring IFX only for luminal disease were excluded. Among them, 30 patients received IFX monotherapy, 36 patients received IFX combined with PSI, and 8 patients were treated with both IFX and immunosuppressants. The average number of IFX infusions was $7.3 \pm 0.5$.

The proportion of patients treated with IFX was significantly higher in the POP group $(33.3 \%$ vs $22.0 \%$, $p=0.044$, Table 1 ). The median time from diagnosis of PD to the first infusion of IFX was shorter among POP patients than AOP patients ( 1 month, IQR: $0.1-1.9$ vs 22 months, IQR: $5.3-38.6, p<0.01$, Table 1$)$. The cumulative probability of IFX therapy at $1,3,5$ and 10 years was 69.1\%, 77.6\%, 79.5\% and $90.4 \%$ in POP patients versus $43.4 \%, 53.7 \%, 57.8 \%$ and $84.7 \%$ in AOP patients, respectively $(p<0.001$, Fig. $2 A)$. No significant differences were detected at numbers of IFX infusion between patients with POP and AOP $(p>0.05$, Table 1$)$.

\section{Surgical treatment}

Forty-eight patients (16.4\%) suffered CD-related intestinal resection after the first diagnosis of PD. The percentage of patients who underwent surgery was significantly higher in the AOP cohort $(21.1 \%$ vs $4.8 \%, p=0.001$, Table 1). However, there was no significant difference in the indication for surgery and the extent of resected intestine between POP and AOP patients $(p>0.05$, Table 1). Furthermore, the cumulative probability of $C D$ related intestinal resection after $C D$ diagnosis was also higher in AOP patients $(9.0 \%$ at 1 year, $12.1 \%$ at 3 years, $18.4 \%$ at 5 years, and $31.8 \%$ at 10 years) than in POP patients $(2.7 \%$ at 1 year, $2.7 \%$ at 3 years, $2.7 \%$ at 5 years, and $8.5 \%$ at 10 years, $p=0.007$, Fig. $2 \mathrm{~B}$ ).

In the multivariate logistic analysis (Table 2), AOP (OR: 4.939, 95\% CI 1.538-15.855, $p=0.007$ ), stricturing behaviour (B2 vs B1, OR: 1.810, 95\% CI 1.008-3.251, $p=0.047$ ) and presence of rectal inflammation (OR: 3.166, 95\% CI 1.119-8.959, $p=0.030$ ) were associated with a higher risk of CD-related intestinal resection among the 293 PCD patients. Other factors, including sex, age at CD diagnosis, PCD diagnostic delay, current smoking status, PD type and disease location, were not associated with CD-related intestinal resection $(p>0.05)$. Furthermore, AOP patients with complex perianal fistulas were more likely to undergo CD-related intestinal 
Table 1 Clinical characteristics of PCD patients with paediatric-onset and adult-onset perianal disease

\begin{tabular}{|c|c|c|c|}
\hline Factors & Patients with POP $(\mathrm{N}=84)$ & Patients with AOP $(\mathrm{N}=209)$ & $P$ value \\
\hline Male, n (\%) & $68(81.0)$ & $154(73.7)$ & 0.228 \\
\hline Mean age at $C D$ diagnosis (years $\pm S D$ ) & $18.0 \pm 4.3$ & $32.0 \pm 10.9$ & $<0.01$ \\
\hline PCD diagnostic delay (months) & $12(2-48)$ & $24(2.5-60)$ & 0.033 \\
\hline Disease location, n (\%) & & & 0.198 \\
\hline $\mathrm{L} 1$, terminal ileum & $19(22.6)$ & $55(26.3)$ & \\
\hline L2, colon & $17(20.2)$ & $62(29.7)$ & \\
\hline L3, ileocolon & $45(53.6)$ & $87(41.6)$ & \\
\hline$\llcorner 4$, upper gastrointestinal tract & $3(3.6)$ & $5(2.4)$ & \\
\hline Disease behaviour, $\mathrm{n}(\%)$ & & & 0.015 \\
\hline B1, non-stricturing, non-penetrating & $56(66.7)$ & $100(47.8)$ & $0.005^{\mathrm{a}}$ \\
\hline B2, structuring & $23(27.4)$ & $88(42.1)$ & $0.024^{a}$ \\
\hline B3, penetrating & $5(6.0)$ & $21(10.0)$ & $0.364^{\mathrm{a}}$ \\
\hline Mean PD onset age (years $\pm S D$ ) & $15.1 \pm 2.9$ & $30.2 \pm 10.5$ & $<0.01$ \\
\hline Perianal fistula, n (\%) & $53(63.1)$ & $110(52.6)$ & 0.119 \\
\hline Complex perianal fistula, n/N (\%) & $38 / 53(71.7)$ & $55 / 110(50.0)$ & 0.011 \\
\hline Perianal abscess, n (\%) & $41(48.8)$ & $100(47.8)$ & 0.898 \\
\hline Hemorrhoids, n (\%) & $16(19.0)$ & $35(16.7)$ & 0.639 \\
\hline Anal ulcer, n (\%) & $3(3.6)$ & $12(5.7)$ & 0.430 \\
\hline Anal fissures, $\mathrm{n}(\%)$ & $5(6.0)$ & $8(3.8)$ & 0.424 \\
\hline Rectovaginal fistula, $\mathrm{n}(\%)$ & $1(1.2)$ & $9(4.3)$ & 0.153 \\
\hline Rectal inflammation, n (\%) & $6(7.1)$ & $24(11.5)$ & 0.268 \\
\hline Current smokers, n (\%) & $4(4.8)$ & $27(12.9)$ & 0.040 \\
\hline Family history of IBD, n (\%) & $4(4.8))$ & $22(10.5)$ & 0.117 \\
\hline \multicolumn{4}{|l|}{ Medications, n (\%) } \\
\hline IFX & $28(33.3)$ & $46(22.0)$ & 0.044 \\
\hline Immunomodulators & $5(6.0)$ & $13(6.2)$ & 0.925 \\
\hline Antibiotics & $51(60.7)$ & $128(61.2)$ & 0.933 \\
\hline Corticosteroids & $3(3.6)$ & $7(3.3)$ & 1.000 \\
\hline Time from PCD diagnosis to first use of IFX, months (IQR) & $1.0(0.1-1.9)$ & $1.8(5.3-38.6)$ & $<0.01$ \\
\hline Numbers of IFX uses (mean \pm SD) & $7.7 \pm 0.75$ & $7.1 \pm 0.6$ & 0.472 \\
\hline History of PSIs, n (\%) & $66(78.6)$ & $150(71.8)$ & 0.245 \\
\hline Frequency of PSIs, n (\%) & & & 0.284 \\
\hline 1 time & $46(54.8)$ & $118(56.5)$ & \\
\hline 2 times & $15(17.9)$ & $22(10.5)$ & \\
\hline 3 times & $5(6.0)$ & $10(4.8)$ & \\
\hline \multicolumn{4}{|l|}{ Types of perianal surgery, $\mathrm{n}(\%)$} \\
\hline Incision and drainage & $33(39.3)$ & $68(32.5)$ & 0.272 \\
\hline Seton insertion & $42(50.0)$ & $83(39.7)$ & 0.107 \\
\hline Fistulectomy & $19(22.6)$ & $52(24.9)$ & 0.764 \\
\hline Proctectomy & $0(0)$ & $2(1.0)$ & 1.000 \\
\hline De-functioning & $1(1.2)$ & $2(1.0)$ & 1.000 \\
\hline Procedure for prolapsing haemorrhoids & $7(8.3)$ & $14(6.7)$ & 0.624 \\
\hline CD-related intestinal resection, n (\%) & $4(4.8)$ & $44(21.1)$ & 0.001 \\
\hline Indication for surgery, n (\%) & & & 0.815 \\
\hline Inflammation & $0(0)$ & $3(6.8)$ & \\
\hline Obstruction & $2(50.0)$ & $19(43.2)$ & \\
\hline Perforation & $1(25.0)$ & $18(40.9)$ & \\
\hline Obstruction combined with perforation & $1(25.0)$ & $4(9.1)$ & \\
\hline Extent of resected intestine, $\mathrm{n}(\%)$ & & & 0.232 \\
\hline Partial ileal resection & $2(50.0)$ & $20(45.5)$ & \\
\hline Partial colon resection & $1(25.0)$ & $2(4.5)$ & \\
\hline Ileocolonic resection & $1(25.0)$ & $22(50.0)$ & \\
\hline
\end{tabular}


Table 1 (continued)

$C D$ Crohn's disease, $P C D$ perianal Crohn's disease, $P D$ perianal disease, $P O P$ paediatric-onset perianal disease, $A O P$ adult-onset perianal disease, $S D$ standard deviation, $I Q R$ interquartile range, $P S I s$ perianal surgical interventions, IFX infliximab, IBD inflammatory bowel disease

${ }^{a}$ This was a subgroup analysis of three disease behaviours between the AOP and POP groups
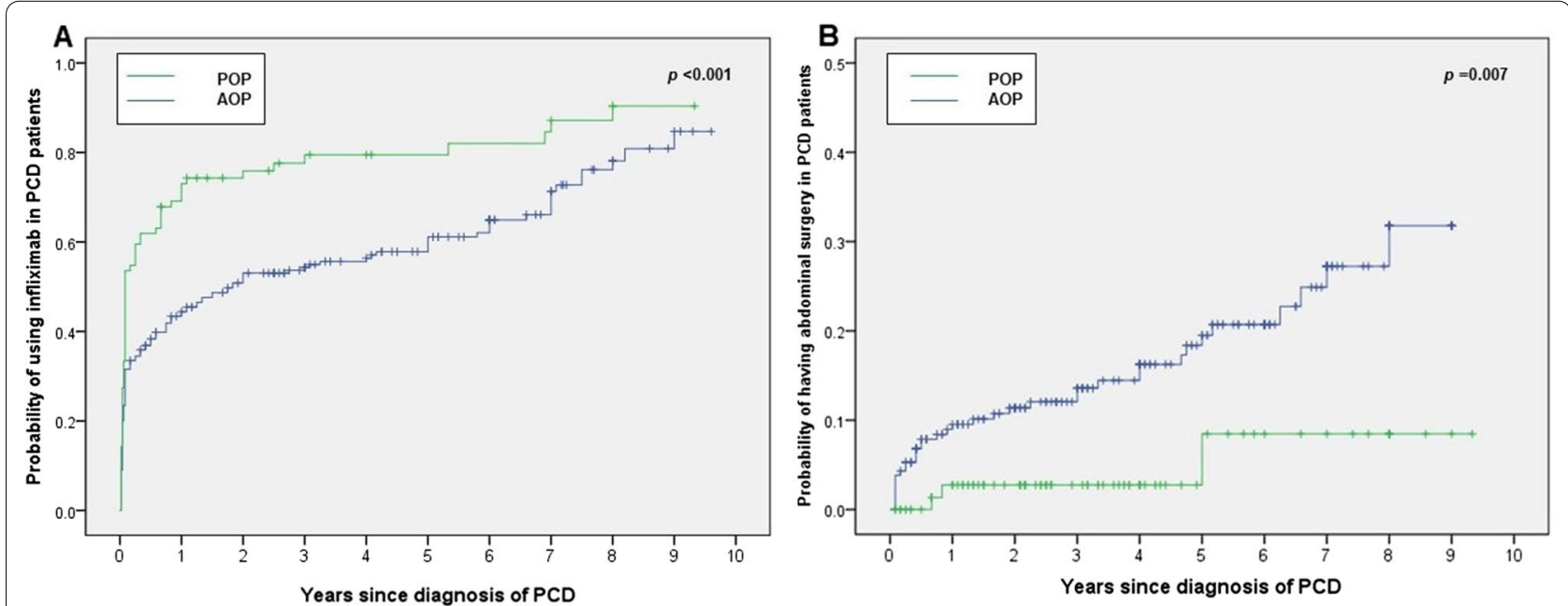

Fig. 2 Cumulative probability of $\mathbf{a}$ infliximab and $\mathbf{b}$ CD-related intestinal resection in patients with paediatric-onset and adult-onset perianal disease. $P C D$ perianal Crohn's disease, $P O P$ paediatric-onset perianal disease, $A O P$ adult-onset perianal disease

Table 2 Factors associated with the risk of intestinal resection

\begin{tabular}{|c|c|c|c|c|}
\hline \multirow[t]{2}{*}{ Factors } & \multicolumn{2}{|l|}{ Univariate analysis } & \multicolumn{2}{|l|}{ Multivariate analysis } \\
\hline & OR $(95 \% \mathrm{Cl})$ & $P$-value & OR $(95 \% \mathrm{Cl})$ & $P$ value \\
\hline \multicolumn{5}{|l|}{ All PCD patients $(n=293)$} \\
\hline Male & 1.727 (0.883-3.379) & 0.110 & $0.488(0.194-1.225)$ & 0.126 \\
\hline AOP & $2.887(1.511-5.515)$ & 0.001 & $4.939(1.538-15.855)$ & 0.007 \\
\hline Behaviour & & 0.019 & & 0.070 \\
\hline$B 2$ versus $B 1$ & 2.097 (1.194-3.685) & 0.010 & $1.810(1.008-3.251)$ & 0.047 \\
\hline$B 3$ versus $B 1$ & $2.329(0.833-6.513)$ & 0.107 & $2.291(0.789-6.651)$ & 0.127 \\
\hline IFX+PSIs & $0.270(0.063-1.163)$ & 0.079 & $0.243(0.049-1.206)$ & 0.083 \\
\hline Rectal inflammation & $2.462(1.050-5.769)$ & 0.038 & 3.166 (1.119-8.959) & 0.030 \\
\hline \multicolumn{5}{|l|}{ Patients with AOP $(n=209)$} \\
\hline PCD diagnostic delay & $0.944(0.986-1.001)$ & 0.109 & $0.994(0.986-1.001)$ & 0.109 \\
\hline Behaviour & & 0.061 & & 0.089 \\
\hline$B 1$ versus $B 3$ & $3.488(0.435-27.976)$ & 0.239 & 3.595 (0.440-29.390) & 0.233 \\
\hline B2 versus B3 & $6.769(0.858-53.416)$ & 0.070 & $6.563(0.817-52.714)$ & 0.077 \\
\hline IFX+PSIs & $0.324(0.073-1.433)$ & 0.138 & $0.374(0.082-1.712)$ & 0.205 \\
\hline Complex perianal fistulas & $2.297(1.089-4.848)$ & 0.029 & $2.257(1.041-4.891)$ & 0.039 \\
\hline \multicolumn{5}{|l|}{ Patients with $P O P(n=84)$} \\
\hline Family history of IBD & $4.102(0.861-19.532)$ & 0.076 & $2.670(0.273-26.148)$ & 0.399 \\
\hline Rectal inflammation & $9.000(2.099-17.210)$ & 0.009 & $7.000(1.876-15.407)$ & 0.012 \\
\hline
\end{tabular}

${ }^{*} C D$ Crohn's disease, $P D$ perianal disease, $B 1$ non-stricturing and non-penetrating, $B 2$ stricturing, $B 3$ penetrating, IFX infliximab, $P S / s$ perianal surgical interventions, $P C D$ perianal Crohn's disease, $A O P$ adult-onset perianal disease, $P O P$ paediatric-onset perianal disease, IBD inflammatory bowel disease 
resection (OR: 2.257, 95\% CI 1.041-4.891, $p=0.039$, Table 2). POP patients with rectal inflammation (OR: 7.000, 95\% CI 1.876-15.407, $p=0.012$ ) had increased risk for CD-related intestinal resection (Table 2).

\section{Trend of clinical characteristics in POP and AOP patients over the 10-year observation period}

From 2008.1 to 2017.12, the proportion of patients receiving IFX treatment increased in both the POP and AOP groups (Fig. 3). The occurrence of CD-related intestinal resection showed a gradually decreasing trend in AOP patients (Fig. 3a). And a negative correlation was found between the proportion of patients receiving IFX treatment and undergoing intestinal resection only in AOP patients $(r=-0.900, p=0.037)$ but not in POP patients $(r=0.667, p=0.219)$.

\section{Discussion}

The presence of $\mathrm{PD}$ in $\mathrm{CD}$ patients usually indicates increasing hospitalization, progression to more complicated disease phenotypes, and high rate of intestinal resection in some studies about Western patients [2, 23, 24]. The growing studies also reported that $\mathrm{PD}$ at the time of $\mathrm{CD}$ diagnosis was more common in Asian countries (33.7-42.4\%) than in some Western countries (13.0$26.9 \%)[13,19,25,26]$. The increasing tendency in China over the past few decades calls for more attention to be paid to the natural course of PCD in these newly developed disease population. However, Chinese studies evaluating the characteristics and outcomes of PCD patients are limited, and the significance of PD development at different ages is unclear. This is the first comparative study to investigate this issue among a Chinese 10-year observational cohort study in the first years of the biologic treatment era. Thus, this study allowed us to obtain key updated knowledge about the differences between PCD patients with paediatric and adult-onset PD concerning the need for intestinal resection. Firstly, we found that $\mathrm{CD}$ patients who developed PD during childhood had a more serious perianal phenotype and earlier PCD diagnosis and IFX treatment, while aggressive luminal disease, current smoking and a higher rate of intestinal resection were more common in AOP patients. Secondly, AOP, stricturing luminal behaviour and rectal inflammation were associated with an increased incidence of intestinal resection. And AOP patients with complex perianal fistulas or POP patients with rectal inflammation were more likely to undergo CD-related intestinal resection. Finally, IFX administration could decrease the rate of intestinal resection in AOP patients. These results indicate that more attention should be paid to AOP patients with complex perianal fistulas and POP patients with rectal inflammation, and highlight the important role of early diagnosis and IFX therapy in achieving better clinical outcomes.

Previous studies have shown that approximately onequarter of CD patients are diagnosed in childhood [16]. Paediatric CD patients usually show distinct features, which are characterized by more severe disease activity and biological therapy than adult CD cases [17, 27]. In our study, $28.7 \%$ of PCD patients developed their first perianal symptoms during the paediatric period, and they presented with more complex perianal fistulas. However, the stricturing phenotype of luminal $\mathrm{CD}$ and $\mathrm{CD}$-related intestinal resection was more common in AOP patients. Thus, early-onset (paediatric-onset) PD presents more complicated local manifestations of PD, but late-onset (adult-onset) PD is more prone to progress to severe luminal damage progression. These results not only indicate distinct clinical characteristics and monitoring focus
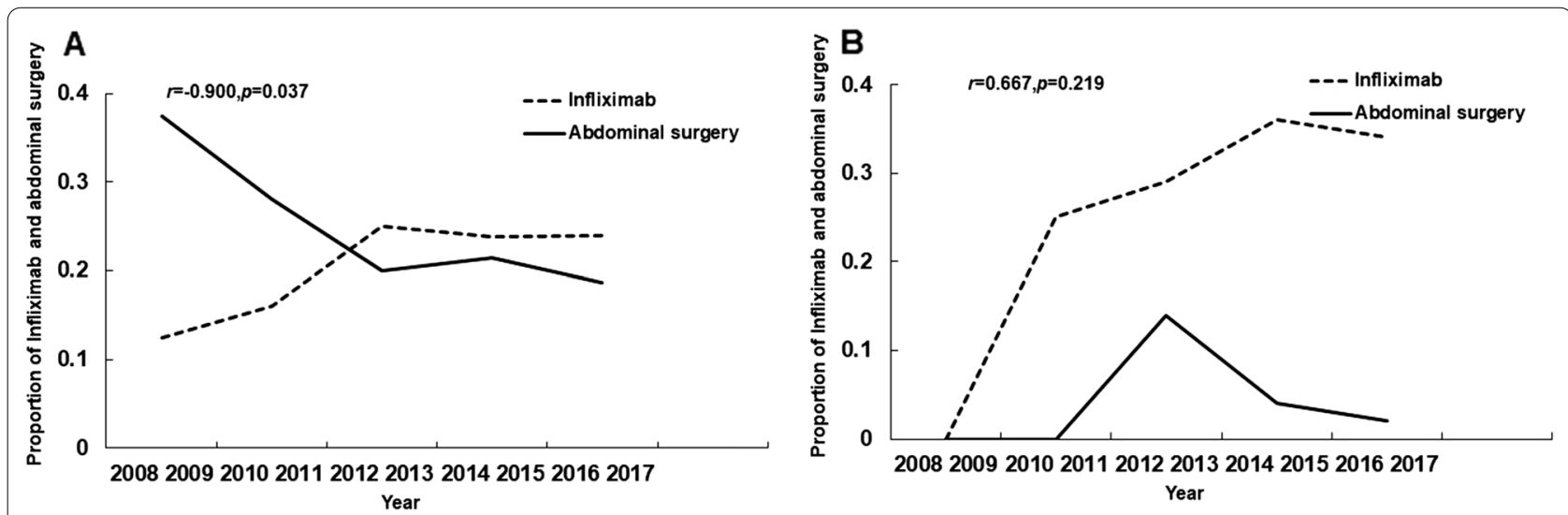

Fig. 3 Ten-year trend and correlation between infliximab and CD-related intestinal resection in CD patients with a adult-onset and $\mathbf{b}$ paediatric-onset perianal disease 
in CD patients who develop PD at different ages but also suggest the presence of distinct disease patterns for perianal and luminal CD.

Moreover, we found that PCD patients with POP had earlier use of IFX and a higher cumulative risk of IFX treatment. In the past decade, IFX was the only available biological agent for Chinese CD patients [28]. Due to its efficacy in treating complicated CD, IFX has been recommended widespread in cases of early-onset or fistulizing PCD as a top-down treatment strategy in recent years [4-10]. We found that POP has been increasing over time, which means there is a trend for POP patients to be diagnosed and treated more recently. PCD diagnosis was performed earlier in POP patients than AOP patients. Therefore, the higher percentage of complex perianal fistulas, early-onset and recent diagnosis of PD in the POP group may contribute to the more frequent and earlier use of IFX.

The presence of PD speeds up the complexity of the natural history of $\mathrm{CD}$, accelerates the development of luminal stenosis, and increases the risk of intestinal resection in some studies of the pre-biologic era [2, 23, 24]. However, most of these studies focused on the adultonset cohort, they neglected the influence of age of the PD development and biological agents on the CD outcomes. Recently, a Korean study reported that the presence of PD at CD diagnosis did not increase the risk for abdominal surgical intervention [13]. And a Danish population-based study found that the occurrence of PD at $\mathrm{CD}$ diagnosis was not predictive of the risk for undergoing intestinal resection, whereas the development of PD during follow-up was [1]. These results raise the possibility that the impact of the PD development time on the intestinal resection of $\mathrm{CD}$ patients may differ. The later the PD developed, the more common the complicated luminal damage and intestinal resection presented. This result is inconsistent with the previous conclusion that the early-onset $C D$ was associated with an increased incidence of CD-related surgery [29]. But our results are similar to a recent study. They showed that there were more intestinal strictures and abdominal operations in adult $\mathrm{CD}$ patients than in paediatric $\mathrm{CD}$ patients, which was related to the longer diagnostic delay in adults [18]. Similarly, we found the patient with AOP (late-onset $\mathrm{PD})$ presented a higher rate of stricturing behaviour and intestinal resection. Factors including AOP, stricturing behaviour and rectal inflammation were predictive for increased CD-related intestinal resection among all PCD patients. The use of IFX treatment also showed a negative correlation with the rate of intestinal resection in patients with AOP. This verified the conclusion that the increased use of biologics is positively correlated with a reduced need for intestinal resection [30]. Furthermore, we observed that the time from the onset of PD to the diagnosis of PCD and the time from the diagnosis of PCD to the first use of IFX were longer in the adult-onset cohort. These results all suggest a later disease course and later IFX treatment in AOP patients. It has become increasingly apparent that the early use of IFX can decrease the occurrence of CD-related surgery in adult CD [19, 31]. Therefore, the more complicated luminal disease, underuse of IFX treatment and delayed initiation of IFX may contribute to the higher rate of intestinal resection in AOP patients.

In addition, smoking has been reported as a definite factor associated with recurrence after surgery and a poor response to medical therapy in $\mathrm{CD}$ patients [32]. Thus, the greater proportion of current smokers also explained the higher rate of intestinal resection in AOP patients. Unexpectedly, both in the univariate and multivariate logistic analysis, we didn't find that current smoking status was significantly associated with CD-related abdominal surgery. This result is inconsistent with previous conclusion. The reason may contribute to a very small samples $(n=4)$ of current smokers in POP patients, and this can lead to the bias in the result. Taken together, these findings indicate that a close monitoring of luminal lesions and a positive therapeutic strategy, including the early and extensive use of IFX treatment and cessation of smoking, should be undertaken in PCD patients with AOP to reduce the rate of intestinal resection.

One of the strengths of our study is the inclusion of all kinds of PCD, leading to a reduction in selection bias. The different clinical characteristics and outcomes of PCD patients with POP and AOP were directly compared in this study. We focused on the influence of PD onset age on the rate of intestinal resection in $C D$ patients, and found that there was a higher risk of intestinal resection in PCD patients who developed PD at adults. These findings should alert physicians to pay close attention to these patients to ensure that they receive intensive treatment and close luminal monitoring to achieve better outcomes in clinical practice.

However, there are some limitations to our study. The first limitation is the retrospective and single-centre design. Secondly, all of the PCD patients included in our study were hospitalized patients, who may have had relatively serious manifestations. Lastly, some $C D$ patients developed PDs in an early time without more detailed records of PSIs. We failed to provide a more specific description of PSIs. So, we can't analyse the influence of different PSIs types on the perianal outcome, which was still needed to be further studied and confirmed.

In summary, $\mathrm{POP}$ and $\mathrm{AOP}$ play different roles in pathogenesis and progression of CD. POP showed 
more complicated perianal lesions than AOP. The clinical impact of PD on the luminal damage of CD patients may be more prominent in patients with AOP than those with POP. Early diagnosis and IFX treatment, as well as closely endoscopic evaluation in $C D$ patients with AOP may therefore allow for earlier identification of potential CD-related luminal damage to reduce the incidence of intestinal resection.

\begin{abstract}
Abbreviations
CD: Crohn's disease; PD: Perianal disease; PCD: Perianal Crohn's disease; IBD: Inflammatory bowel disease; POP: Paediatric-onset PD; AOP: Adultonset PD; TNF: Tumour necrosis factor; IFX: Infliximab; PSIs: Perianal surgical interventions.
\end{abstract}

\section{Acknowledgements}

The authors thank all patients and colleagues of Shanghai Tenth People's Hospital for their support.

\section{Authors' contributions}

Haichao Wang, Chen Ye and Xiaolei Wang designed this study. Haichao Wang, Chen Ye, and Yaling Wu collected and interpreted the data. Haichao Wang and Yaling Wu analysed the data. All authors contributed to drafting the article. Zhanju Liu was responsible for critically revising the article. Xiaolei Wang was responsible for all the data and results in this study and the eventual revision of the entire paper. All authors have approved the final version of this manuscript.

\section{Funding}

This study was supported by a grant from the National Natural Science Foundation of China (Grant No. 81970449).

\section{Availability of data and materials}

The datasets used and analysed during the current study available from the corresponding author on reasonable request.

\section{Declarations}

\section{Ethics approval and consent to participate}

The study complied with the Helsinki Declaration, and the study protocol and exemption of informed consent were approved by the Institutional Ethics Committee of the Tenth People's Hospital of Tongji University, Shanghai, China (SHSY-IEC-4.0/19-23/01).

\section{Consent for publication}

Not applicable.

\section{Competing interests}

The authors declare that the research was conducted in the absence of any commercial or financial relationship that could be construed as a potential conflict of interest.

\section{Author details}

'Department of Gastroenterology, Shanghai Tenth People's Hospital, School of Medicine, Tongji University, Shanghai 200072, China. ${ }^{2}$ Medical College of Soochow University, Suzhou 215000, Jiangsu Province, China.

Received: 24 January 2021 Accepted: 8 October 2021

Published online: 14 October 2021

\section{References}

1. Zhao M, Lo BZS, Vester-Andersen MK, Vind I, Bendtsen F, Burisch J. A 10-year follow-up study of the natural history of perianal Crohn's disease in a Danish population-based inception cohort. Inflamm Bowel Dis. 2019;25(7):1227-36.

2. Yoon JY, Cheon JH, Park SJ, Kim TI, Kim WH. Effects of perianal involvement on clinical outcomes in Crohn's disease over 10 years. Gut Liver. 2018;12(3):297-305.

3. Moon CM, Park DI, Kim ER, Kim YH, Lee CK, Lee SH, et al. Clinical features and predictors of clinical outcomes in Korean patients with Crohn's disease: a Korean association for the study of intestinal diseases multicenter study. J Gastroenterol Hepatol. 2014;29(1):74-82.

4. Keljo DJ, Markowitz J, Langton C, Lerer T, Bousvaros A, Carvalho R, et al. Course and treatment of perianal disease in children newly diagnosed with Crohn's disease. Inflamm Bowel Dis. 2009;15(3):383-7.

5. Gupta N, Bostrom AG, Kirschner BS, Ferry GD, Gold BD, Cohen SA, et al. Incidence of stricturing and penetrating complications of Crohn's disease diagnosed in pediatric patients. Inflamm Bowel Dis. 2010;16(4):638-44.

6. Singer AA, Gadepalli SK, Eder SJ, Adler J. Fistulizing Crohn's disease presenting after surgery on a perianal Lesion. Pediatrics. 2016;137(3):e20152878.

7. Vernier-Massouille G, Balde M, Salleron J, Turck D, Dupas JL, Mouterde $\mathrm{O}$, et al. Natural history of pediatric Crohn's disease: a population-based cohort study. Gastroenterology. 2008;135(4):1106-13.

8. Panaccione R, Rutgeerts P, Sandborn WJ, Feagan B, Schreiber S, Ghosh S. Review article: treatment algorithms to maximize remission and minimize corticosteroid dependence in patients with inflammatory bowel disease. Aliment Pharmacol Ther. 2008;28(6):674-88.

9. Danese S, Colombel JF, Reinisch W, Rutgeerts PJ. Review article: infliximab for Crohn's disease treatment-shifting therapeutic strategies after 10 years of clinical experience. Aliment Pharmacol Ther. 2011;33(8):857-69.

10. Loly C, Belaiche J, Louis E. Predictors of severe Crohn's disease. Scand J Gastroenterol. 2008:43(8):948-54.

11. Dupont-Lucas C, Dabadie A, Alberti C, Ruemmele FM, Pediatrique G. Predictors of response to infliximab in paediatric perianal Crohn's disease. Aliment Pharmacol Ther. 2014;40(8):917-29.

12. Sands BE, Anderson FH, Bernstein CN, Chey WY, Feagan BG, Fedorak RN, et al. Infliximab maintenance therapy for fistulizing Crohn's disease. N Engl J Med. 2004;350(9):876-85.

13. Song EM, Lee HS, Kim YJ, Oh EH, Ham NS, Kim J, et al. Clinical outcomes and long-term prognosis of perianal Crohn's disease in an Asian population. J Gastroenterol Hepatol. 2020.

14. Law ST, Li KK. Age-related differences in the clinical course of Crohns disease in an Asian population: a retrospective cohort review. Indian Pediatr. 2013:50(12):1148-52.

15. Mao R, Tang RH, Qiu Y, Chen BL, Guo J, Zhang SH, et al. Different clinical outcomes in Crohn's disease patients with esophagogastroduodenal, jejunal, and proximal ileal disease involvement: is $L 4$ truly a single phenotype? Ther Adv Gastroenterol. 2018;11:1756284818777938.

16. Henderson P, Russell RK, Satsangi J, Wilson DC. The changing epidemiology of paediatric inflammatory bowel disease. Aliment Pharmacol Ther 2011;33(12):1380-1 (author reply 1-2).

17. Pigneur B, Seksik P, Viola S, Viala J, Beaugerie L, Girardet JP, et al. Natural history of Crohn's disease: comparison between childhood- and adultonset disease. Inflamm Bowel Dis. 2010;16(6):953-61.

18. Schoepfer A, Santos J, Fournier N, Schibli S, Spalinger J, Vavricka S, et al. Systematic analysis of the impact of diagnostic delay on bowel damage in paediatric versus adult onset Crohn's disease. J Crohns Colitis. 2019;13(10):1334-42.

19. Herman Y, Rinawi F, Rothschild B, Nir O, Shamir R, Assa A. The characteristics and long-term outcomes of pediatric Crohn's disease patients with perianal disease. Inflamm Bowel Dis. 2017;23(9):1659-65.

20. Ibd Working Group of the European Society for Paediatric Gastroenterology H, Nutrition. Inflammatory bowel disease in children and adolescents: recommendations for diagnosis - the Porto criteria. J Pediatr Gastroenterol Nutr. 2005;41(1):1-7.

21. Gomollon F, Dignass A, Annese V, Tilg H, Van Assche G, Lindsay JO, et al. 3rd European evidence-based consensus on the diagnosis and management of Crohn's Disease 2016: part 1: diagnosis and medical management. J Crohns Colitis. 2017;11(1):3-25.

22. Sandborn WJ, Fazio VW, Feagan BG, Hanauer SB, American Gastroenterological Association Clinical Practice C. AGA technical review on perianal Crohn's disease. Gastroenterology. 2003;125(5):1508-30. 
23. Chun J, Im JP, Kim JW, Lee KL, Choi CH, Kim H, et al. Association of perianal fistulas with clinical features and prognosis of Crohn's Disease in Korea: results from the CONNECT study. Gut and liver. 2018;12(5):544-54.

24. Xavier S, Curdia Goncalves T, de Castro FD, Magalhaes J, Rosa B, Moreira MJ, et al. Perianal Crohn's disease - association with significant inflammatory activity in proximal small bowel segments. Scand J Gastroenterol. 2018;53(4):426-9.

25. Mak WY, Mak OS, Lee CK, Tang W, Leung WK, Wong MTL, et al. Significant medical and surgical morbidity in perianal Crohn's disease: results from a territory-wide study. J Crohns Colitis. 2018;12(12):1392-8.

26. Eglinton TW, Barclay ML, Gearry RB, Frizelle FA. The spectrum of perianal Crohn's disease in a population-based cohort. Dis Colon Rectum. 2012;55(7):773-7.

27. Paul T, Birnbaum A, Pal DK, Pittman N, Ceballos C, LeLeiko NS, et al. Distinct phenotype of early childhood inflammatory bowel disease. J Clin Gastroenterol. 2006:40(7):583-6.

28. Park EJ, Song KH, Baik SH, Park JJ, Kang J, Lee KY, et al. The efficacy of infliximab combined with surgical treatment of fistulizing perianal Crohn's disease: comparative analysis according to fistula subtypes. Asian J Surg 2018:41(5):438-47.
29. Romberg-Camps MJ, Dagnelie PC, Kester AD, van de Kruijs MAH, Cilissen $M$, Engels LG, et al. Influence of phenotype at diagnosis and of other potential prognostic factors on the course of inflammatory bowel disease. Am J Gastroenterol. 2009;104(2):371-83.

30. Brunet E, Vela E, Melcarne L, Cleries M, Pontes C, Llovet LP, et al. Time trends of Crohn's disease in catalonia from 2011 to 2017. Increasing use of biologics correlates with a reduced need for surgery. J Clin Med. 2020;9(9).

31. Thia KT, Sandborn WJ, Harmsen WS, Zinsmeister AR, Loftus EV Jr. Risk factors associated with progression to intestinal complications of Crohn's disease in a population-based cohort. Gastroenterology. 2010;139(4):1147-55.

32. Parkes GC, Whelan K, Lindsay JO. Smoking in inflammatory bowel disease: impact on disease course and insights into the aetiology of its effect. J Crohns Colitis. 2014;8(8):717-25.

\section{Publisher's Note}

Springer Nature remains neutral with regard to jurisdictional claims in published maps and institutional affiliations.
Ready to submit your research? Choose BMC and benefit from:

- fast, convenient online submission

- thorough peer review by experienced researchers in your field

- rapid publication on acceptance

- support for research data, including large and complex data types

- gold Open Access which fosters wider collaboration and increased citations

- maximum visibility for your research: over $100 \mathrm{M}$ website views per year

At BMC, research is always in progress.

Learn more biomedcentral.com/submissions 